\title{
Technical project for a new water purification solution
}

\author{
Adina Toma ${ }^{1, *}$, Zheleva Ivanka $^{2}$, Cristian Puşcaşu ${ }^{1}$, Alexandru Paraschiv $^{1}$ and Mihaela \\ Grigorescu $^{1}$ \\ ${ }^{1}$ COMOTI - Romanian Research and Development Institute for Gas Turbines, Gas Turbines Special \\ Components. Physics and Mechanic Testing Department, 220D Iuliu Maniu, 061126 Bucharest, \\ Romania \\ ${ }^{2}$ University of Ruse „Angel Kanichev”, 8 Studentska, 7017, Russe, Bulgaria
}

\begin{abstract}
This research is part of the RO-BG Cross-Border Cooperation Program, project "CLEANDANUBE", MIS-ETC 653, which has finalised by providing a common strategy to prevent the Danube's pollution technological risks with oil and oil products. This paper presents a new sustainable water purification solution. A short introduction will be offered and an overview regarding the research and new methods to greening the waste is provided. The theoretical aspects of the centrifugal separation phenomenon are studied and the preliminary project bases were established. The paper conveys the possible constructive variations and the technological implications of those. Ultimately, the technical project for a new water purification solution and conclusions with critical points encountered during the designing phase are presented.
\end{abstract}

\section{Introduction}

All EU countries use a common approach for river basin management conveyed by the adoption of the EU Water Framework Directive (2000/60/EC) [1], and based on this; a Management Plan of Danube River Basin was elaborated. The plan focuses on key border issues, so-called significant management issues (which may directly or indirectly affect the quality of rivers, lakes and groundwater bodies across borders): Organic pollution; Pollution from nutrients; Pollution with hazardous substances; and Hydro morphological alterations.

From all forms of pollution, the most severe impact on water has pollution with oil during transportation, although it represents only $24 \%$ of the pollution causes.

The presence of oil waste is a major problem in terms of environmental factors, as well as economic. These wastes are hazardous for fauna and flora and further investment development is needed to greening the affected areas. Waste oil composition is diverse, depending on the types of waste and stock of origin and the nature of oil spilled.

Analyzing the risk factors of shipping accidents that cause oil pollution, we can highlight the categories: Risks arising from physical and chemical properties of certain

\footnotetext{
*Corresponding author: adina.toma@,comoti.ro
} 
dangerous goods carried, including oil and petroleum products; Risks of hidden defects caused by the vessel; and Risks caused by human mistakes.

Waste oil has a composition consisting basically of three compounds phase's types:

- The first part consists of phase oil and contains various species of heavy hydrocarbon compounds and resins or asphalt category.

- The second phase consists of water in various minerals that are dissolved.

- The third phase consists of mineral compounds that are in solid phase. Separation of the three phases is a difficult technical problem and is realized with high costs.

The novelty of the solutions presented in this paper is an entirely different technology (centrifugation), that will complement and improve the existing ones, in order to minimize the effects of pollution, the response time and the intervention time in case of pollution, as well as to increase in the same time the capability and efficiency of the separation process for those three phases.

\section{Theoretical aspects of the centrifugal separation phenomenon}

The new water purification solution proposes the use of the most effective and used multiphase mixtures separation method based on the difference between the different specific weights of the components. In most cases the system is non-invasive (does not require chemical treatment than in cases of catastrophic spills).

Centrifugal separation is the division of the constituents of a heterogeneous mixture, different based on their specific weight, using centrifugal force created during rotation.

Decanter centrifuge separates by specific gravity liquids, spilling the top, centre, easy fluid, and one hard on the periphery. In the same manner can be employed the separation of a liquid which has solid particles in suspension. Speed centrifuges can reach up to 60,000 revolutions per minute (ultracentrifuge). Separation is facilitated by dividing the conical liquid layer by means of conical plates.

For components with different densities the separator works only by sedimentation, a process that produces the separation of liquids and solids in suspension due to the difference in density. If the density difference is large, then gravity can provide enough force for separation to occur within a reasonable time - as is the case with large tanks or blades separators. If the density difference is small, then it would take too much gravitational separation, and separation force must be increased by adding the centrifugal forces several times higher than that of gravity. Centrifugal force can be created either by the flow of the mixture as a hydro cyclone or mechanically driven rotation, as in sedimentation centrifuges. Centrifugal separator can be used for most types of liquid/solid, given its ability to handle a variety of different mixtures and concentrations. The separator can be used for three phase separation in which liquid is composed of water and oil. It can be operated so as to give a high degree of separation.

In order to design such solution, first of all we must understand the centrifugal forces.

Centrifugal acceleration developed inside the cylinder radius $\mathrm{r}$ and angular rotational speed " $\omega$ " is:

Centrifugal force is:

$$
a=r \omega^{2}
$$

$$
\begin{array}{r}
G=\frac{r \omega^{2}}{\mathrm{~g}} \\
G=\frac{r}{g}\left(\frac{2 \pi n}{60}\right)^{2} \\
G=\frac{n^{2} \emptyset}{1800}
\end{array}
$$


Where: $r=$ container inner radius [m]

$\omega=$ angular speed $\left[\mathrm{rad} / \mathrm{sec}^{2}\right]$

$\mathrm{g}=$ gravitational acceleration $=9.81\left[\mathrm{~m} / \mathrm{sec}^{2}\right]$

$\mathrm{n}=$ container speed [rpm]

$360^{\circ}=6.287$ radian

$\mathrm{S}$, the slippage force (figure 1) is:

$$
S=\sin \alpha G
$$

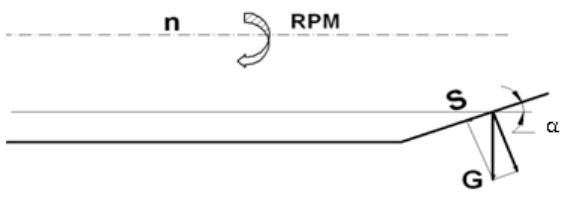

Fig. 1. Slippage force

The equivalent surface (sigma value) is:

$$
\Sigma=\frac{1}{160} n^{2} L_{c y l} r^{2}
$$

Where;

$\Sigma=$ sigma value $\left[\mathrm{m}^{2}\right]$

$\mathrm{n}=$ Container speed [rpm]

Lcyl $=$ barrel length $[\mathrm{m}]$

$\mathrm{r}=$ maximum radius of cylinder (half diameter) [m]

Sigma value is the equivalent surface in sq. $\mathrm{m}$ of a static flotation tank to produce the same solid/liquid separation results.

\section{Dewatering surface}

Dewatering surface $\left[\mathrm{m}^{2}\right]$ is the surface of the cylinder section (the cylindrical portion):

Where:

$$
A_{c, n}=\pi D L_{c y l}=\frac{\Sigma}{G}
$$

$A_{c, n}=$ Decanter surface settling $\left[\mathrm{m}^{2}\right]$

$\Sigma=$ sigma value $\left[\mathrm{m}^{2}\right]$

$\mathrm{G}=$ centrifugal force

$\mathrm{D}=$ internal diameter $[\mathrm{m}]$

$\mathrm{L}_{\mathrm{cyl}}=$ length of the longitudinal section [m].

\section{The dewatering volume}

Centrifugal separator dewatering volume is obtained assuming the total volume of liquid in the cylinder of the container. This volume is a function of surfaces diameter (figure 2).

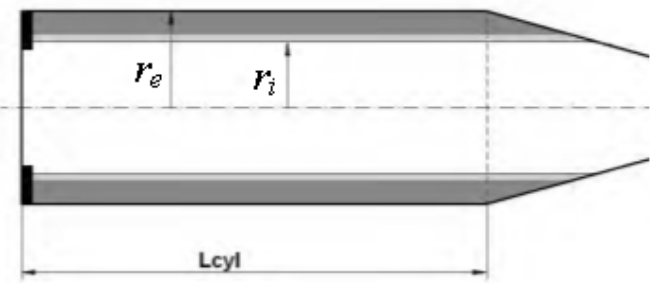

Fig. 2. Centrifugal separator dewatering volume scheme

To calculate the dewatering volume cylindrical one must take into a consideration the cylindrical length $\mathrm{L}_{\mathrm{cyl}}$, the container inner radius $\mathrm{r}_{\mathrm{e}}[\mathrm{m}]$ and the $\mathrm{r}_{\mathrm{i}}[\mathrm{m}]$, where $\mathrm{r}_{\mathrm{i}}$ is approx. $=$ $60 \% \mathrm{r}_{\mathrm{e}}$.

Dewatering volume is:

Retention time:

$$
D_{v}=\left(r_{e}^{2}-r_{i}^{2}\right) \pi L_{c y l}\left[\mathrm{~m}^{3}\right]
$$


Where:

$$
R_{t}=\frac{3600 V_{t d}}{Q_{\text {input }}}
$$

$\mathrm{R}_{\mathrm{t}}=$ retention time

$\mathrm{V}_{\mathrm{td}}=$ container total dewatering volume

$\mathrm{Q}_{\text {input }}=$ Slurry feed rate $[\mathrm{l} / \mathrm{h}]$

The retention time is the time in which the liquid remains in the container before being discharged. Retention time depends on characteristics of the feed slurry like this:

- specific weight of solid;

- viscosity of liquid phase

- amount of substance treatment.

Longer retention time will result in more efficient solid/liquid separation.

Depending on water quality by introducing a speed differences between roller and separator conveyor within walking distance increases and hence the quality of the separation process. Efficiency of separation is achieved by changing $\Delta_{\mathrm{n}}$, where $\Delta_{\mathrm{n}}$ is the differential between the cylinder and conveyor speed.

\section{The power required to drive the centrifuge}

- For training centrifuges power consumption involved the following:

- $\mathrm{N}_{\mathrm{a}}$ power required to bring the masses in motion, from sleep mode to speed;

- $\mathrm{N}_{\mathrm{b}}$ power required to bring the liquid to the centrifuge at the speed of system;

- $\mathrm{N}_{\mathrm{c}}$ power to overcome friction in the spinning shaft bearings;

- $\mathrm{N}_{\mathrm{d}}$ power to overcome friction between the centrifugal and ambient air;

- $\mathrm{N}_{\mathrm{e}}$ power for other resistance to overcome, eg scrapers which remove sediment friction (in centrifuges with continuous operation), the friction in the flow of fluid through the centrifuge, etc.

The starting power is:

$$
N_{p}=N_{a}+N_{b}+N_{c}+N_{d}+N_{e}
$$

Nominal power for discontinuous centrifuges is:

$$
N_{r, c}=N_{c}+N_{d}
$$

Nominal power for continuous centrifuges is:

$$
N_{r, c}=N_{b}+N_{c}+N_{d}+N_{e}
$$

Nominal power system is therefore lower than the starting power. The starting power is even greater as the starting time (up to the speed of the system) is smaller.

More details regarding the theoretical aspects of the centrifugal separation phenomenon can be found in the "Study on the designation of technological parameters and constructive to be attained" [2].

\section{Possible constructive variations and the technological implications}

Technologically, the water purification solution must meet the following conditions: to be provided with a floating system to maintain it over the level of water; to create a barrier that will not allow the crossing of polluted waters downstream; to be provided with a admission system for the polluted waters with a rough preliminary filtration of the collected products.

The filtration system must be dimensioned in such a way to allow the crossing of designed flow in the quantity and quality needed for the suction pump to function.

The suction pump must ensure the designed flow for the centrifugal installation. For a medium capacity installation, as it results from the study began for stage 3 of the project $\left(15 \div 25 \mathrm{~m}^{3} / \mathrm{h}\right)$, it must ensure an adjustable output pressure of $4 \div 7 \mathrm{bar}$. 
The dimensioning of the building elements of the separator that will match the functional requirements (designed flow for processing polluted water).

The achievement of some variable speeds $n_{c}$ (speed of the separator housing) and $n_{i}$ (speed from the entry in the differential gearbox) so the speed difference $\Delta \mathrm{n}$ between cylinder and transporter can process the separation for every features of the polluted element. One solution that was studied for the research theme was sedimentation centrifuge with horizontal screw (figure 3) [3].
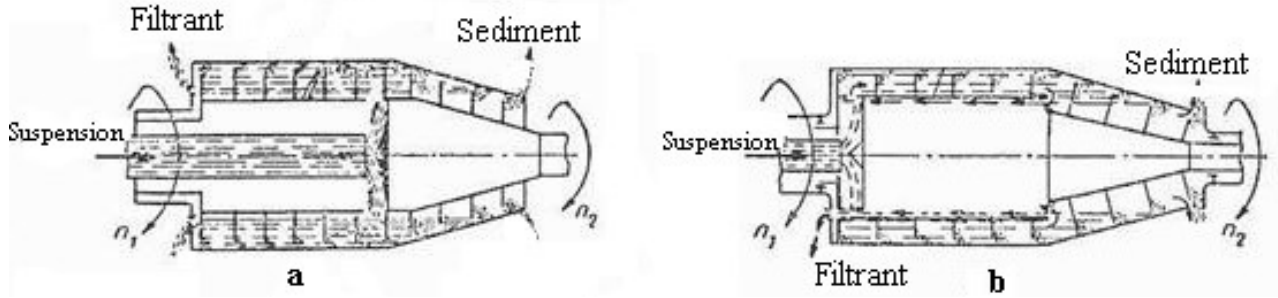

Fig. 3. Screw centrifuge functioning sketch a) in counter-current; b) in echi- current

Other solutions, as a result of the numerous working conditions, imposed by the raw material and the resulted products, were several types of centrifuges (table 1).

Table 1- Centrifuge classification

\begin{tabular}{|l|l|}
\hline Classification criteria & Classification groups \\
\hline Separation power (efficiency factor $\mathrm{z})$ & $\begin{array}{l}\text { Normal Centrifuge }(\mathrm{z}<3000) \\
\text { Super centrifuge }(\mathrm{z}>3000) \\
\text { Ultracentrifuge }\left(\mathrm{z}>5 \cdot 10^{5}\right)\end{array}$ \\
\hline Centrifugation purpose & $\begin{array}{l}\text { Filtering the granular or crystalline suspensions / } \\
\text { Suspensions sedimentation / Emulsion separation }\end{array}$ \\
\hline Function & Discontinuous (in batch) / Continuous \\
\hline Download ( precipitate evacuation) & $\begin{array}{l}\text { Manual / By gravitation, at low speed / With pulsed } \\
\text { pistons / With spiral conveyer / With knives and scrapers } \\
\text { / By centrifugal force / Hydraulics }\end{array}$ \\
\hline Axis position & Vertical / Horizontal / Oblique \\
\hline The support of the centrifuge & Suspended / Supported \\
\hline Operation & Upper / Lower \\
\hline
\end{tabular}

These centrifuges are characterized by a perforated brake drum, lining with mesh or cloth. They serve to filter suspensions, separation of crystals from initial solution, drying the textiles and are indicated for separating suspensions that needs o long period for centrifugation and washing. Developing several possible constructive variants, analysing concomitant the technologic implications was very complex to be performed because it has a multidisciplinary character (chemistry, material sciences, fluid mechanics, fluid flows in machines with rotating blades, oppositions of materials, etc.). This activity concluded with a final project theme, to achieve the technical project for a new water purification solution.

\section{Preliminary project basis}

The centrifugal separation installation must meet the next general requirements:

- to be efficient and adaptive to the goal; to be the most simple in construction; and to be not so expensive in exploitation, regarding the energy consumption and the raw materials and materials needed. For the designation of the technological and constructive parameters needed to develop the preliminary project theme, first it must be defined the final technological scheme and then the adopted constructive solution. The most appropriate technological scheme for the proposed application is the one from figure 4 . In order to 
estimate in a correct way the dimensions of the storage capacity for the solid components, an analysis over the solid phase concentration of Danube's water both in the normal and in flooding period must be carried out.

Following the analysis over the constructive solutions adaptable to the goal of the CLEANDANUBE project, the solution of a centrifugal separator in a horizontal position is the most convenient, both constructive and functional. In figure 5 is represented the general scheme of a centrifugal separator. The centrifugal separator is in principle a quite simple device, although is far from being easy to build. Has in his composition a rotating cylinder and an interior transport screw, the separate liquids getting out at one end and the solids at the opposite end. The first quality of the separator is its capacity to remove large amounts of suspended solids from a mixture of liquids, with a reasonable low level of retained liquid in removed solids. This apparent simplicity of the separator is complicated by the diverse range of projects variations.

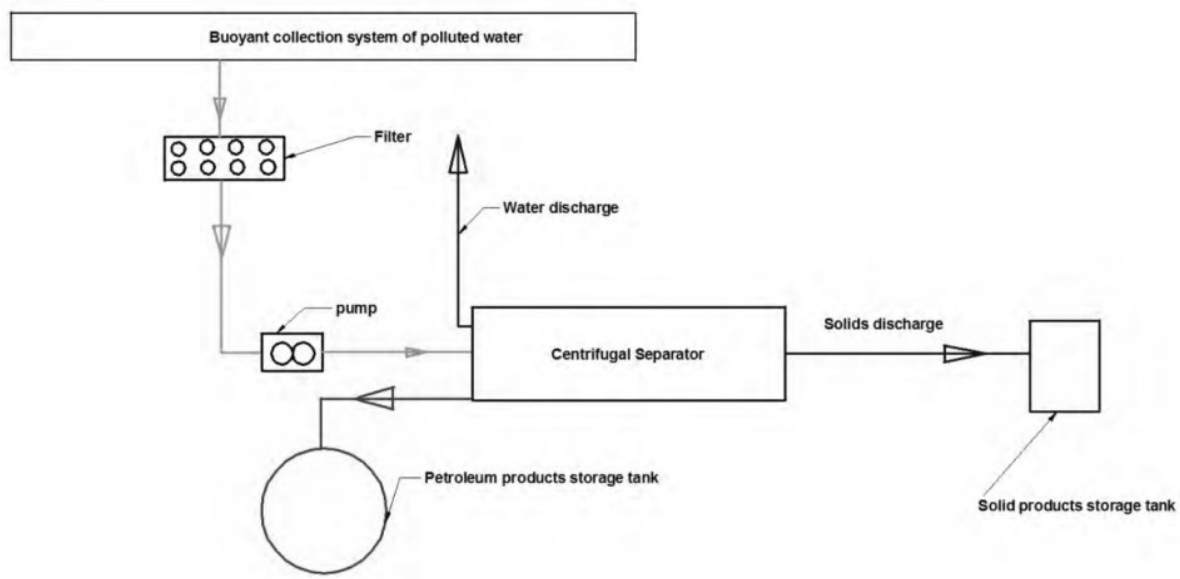

Fig. 4. The general scheme for the petroleum wastes separation system

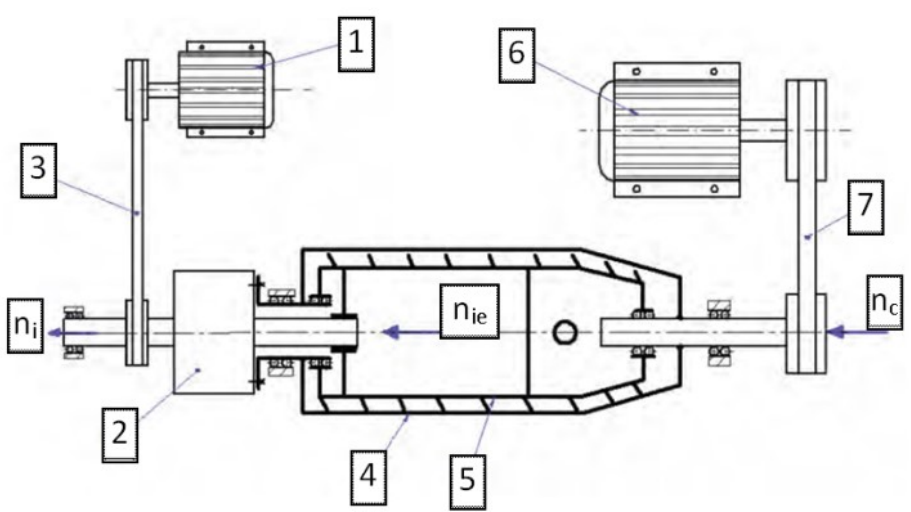

Fig. 5. General scheme of a centrifugal separator (1-Differential gear drive motor; 2-Differential gear; 3-Belt drive differential gear input shaft; 4 - Container; 5-Conveyor ans.; 6- Centrifugal container drive motor; 7- Centrifugal container belt drive; $\mathrm{n}_{\mathrm{c}}$ rotational container speed [rpm]; $\mathrm{n}_{\mathrm{i}}$ - rotational speed of a differential gear input shaft $[\mathrm{rpm}] ; \mathrm{n}_{\mathrm{e}}$ - rotational conveyor speed [rpm] ) 


\section{Technical project for a new water purification solution}

Following previous presented aspects on the development of technological and constructive parameters and effective technological schemes to prevent and remove the effects of pollution the Danube, were determined technical conditions for the design and construction of treatment plants based mainly on centrifugal separation technology.

In figure 6 is represented overall design of the separation plant.

The centrifugal separator designed in the context of this research can be used both as solid-liquid phase separator, and is part of decanters (used for clarification of liquids) or three-phase separator consisting of two immiscible liquids and solid and are known as the tricanters.

Materials of construction of the centrifugal separator are many and varied. It is more usual to make the contact parts, particularly in the rotating assembly, of some form of stainless steel. This is to avoid assembly problems and misalignment due to corrosion on mating surfaces. This has to be avoided with high speed rotating equipment.

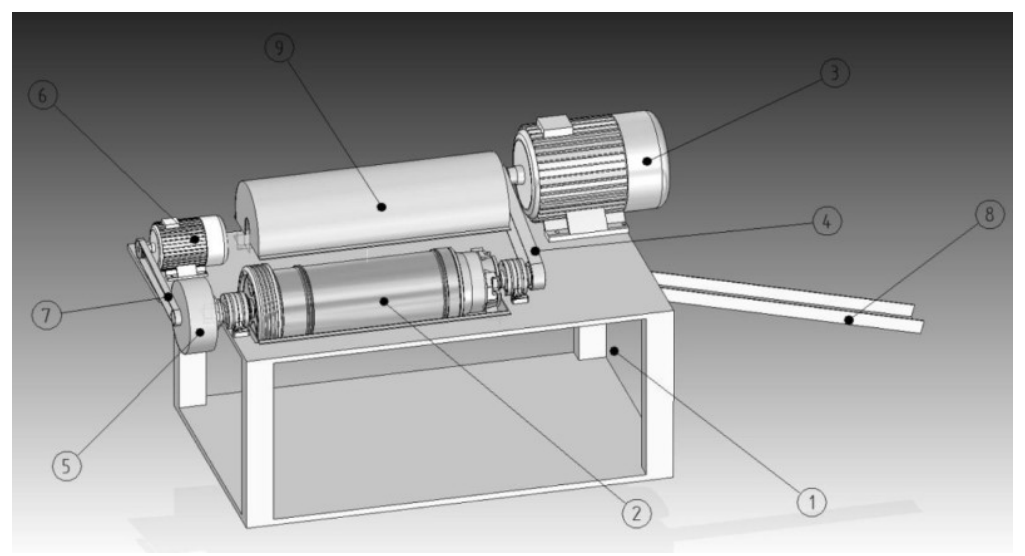

Fig. 6. General configuration of the installation of centrifugal separation (1-Frame; 2-Centrifugal separator; 3-Main drive; 4-Belt drive centrifuge container; 5-Gearbox; 6-Gearbox drive motor; 7-Belt drive gearbox; 8- Guide for solid discharge; 9-Casing)

Nevertheless, it must be said that there are many centrifugal separators in operation with bowls of carbon steel, where their manufacturer claims to be able to overcome, or avoid, corrosion. For stationary contact components there is no need for a high grade of stainless steel. When the process used is non-arduous, simple neoprene seals and gaskets will suffice. Supporting framework will be in ordinary or even cast steel. For parts that goes into housing and screw austenitic steel $316 \mathrm{~L}$ is chosen.

The research comprises also the standard and auxiliary elements that go into water infested with petroleum products treatment plants and the documentation of detailed execution. Auxiliary devices that go into the system are the following (figure 7): Protectivebarrier systems (dams); Infested water collection system; Drives a centrifugal separator plant; Storage system of processed products; Instrumentation and control of technological process. 


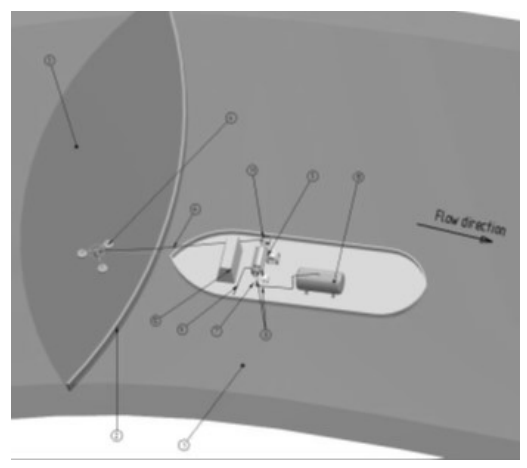

Fig. 7. Overview of an ship-mounted installation for the recovery of petroleum products spilled in the waters of the Danube (1-Danube river; 2-Protective-barrier systems; 3-Wastewater; 4-Infested water collection system; 5-Centrifugal separator assembly; 6- Infested water pipe; 7-Oil pump; 8-Recovered oil pipeline; 9-Water discharge pipe; 10-Oil tank; 11- Solids collection tank; 12-Control panel)

In principle, the technological flow for treating water contaminated with petroleum products in marine accidents includes the following operations:

a) Information, Warning.

b) Measures to stop pollution and limit the polluted area.

c) Monitoring. The initial phase of monitoring is to determine pollutants by analysis of samples, analyses that will be resumed in the terminal phase to confirm the completion of remediation and the possibility of recovering the water and the solid part without the oil component, which is stored separately. Depending on the appearance and colour of the oil slick on the water surface, we can determine the thickness (volume) of the pollutant. Surveillance of the area will continue after the completion of works by checking for anything that may have been overlooked. According to the initial observations a method of intervention is defined in order to be applied (minor or major intervention).

d) Isolating the contaminated area.

e) Recovering the water polluted with oil products.

f) Processing and separating the composing phases of the polluting mixture.

g) Controlling and appreciating the decontamination.

\section{Conclusions}

The water and solids must be restored in the environment and petroleum stored for transport. According to oil waste centrifuging systems, three steady phases result that must be verified and enclosed within legal limits of use restoration or source discharge.

Water resulted from centrifuging must be verified to abide legal requirements for used water discharge by means of quality indicators for waste water provided by legislation in force. The proposed solution involves processing, on-site contaminated water with oil products and reintegration into the natural circuit of water and solid components, oil obtained being taken into special tanks, total and immediate problem solving. This is possible using special centrifugal processing equipment of water polluted with oil in one step and the separation into organic products, solid water and oil. 
During CLEANDANUBE implementation, critical points were encountered, both technological and administrative. From technological view the challenging was given by the particularity of the Danube river, because the solution is perfectly adapted to be used in Romania-Bulgaria cross border. From administrative point of view, the bureaucracy of the entire process, from signing the contract to implement him and even now, to assure his sustainability it is a burdensome process. The most challenging is to find founds in order to implement the solution along the Danube cross-border.

\section{References}

1. Directive 2000/60/EC of the European Parliament and of the Council establishing a framework for the Community action in the field of water policy, modified by 2008/32/CE, 2008/105/CE and 2009/31/CE Directives and 2455/2001/CE Decision

2. C. Puscasu, I. Zheleva et all, Study 2, Study on the designation of technological parameters and constructive to be attained, Common strategy to prevent the Danube's pollution technological risks with oil and oil products - CLEANDANUBE, Operation: no.2(2i)-2.2-5, code MIS-ETC 653, 2010

http://www.comoti.ro/en/participarea_la_proiecte_europene_2_11.htm

3. C.Puscasu, I. Zheleva, et all, Study 3, Study on possible constructional versions, technological implications, Common strategy to prevent the Danube's pollution technological risks with oil and oil products - CLEANDANUBE, Operation: no.2(2i)2.2-5, code MIS-ETC 653, (2011) 